\title{
Study Of The Heat Recovery Potential Of Water-to-air Heat Pumps In A Closed-loop System In Office Buildings
}

\author{
J.F. Belmonte ${ }^{1,2}$, M. Díaz-Heras ${ }^{1}$, J.D. Moya-Rico ${ }^{1}$, J.I. Córcoles ${ }^{1,2}$ \\ A. Molina ${ }^{1,2}$, J.A. Almendros-Ibáñez ${ }^{1,2}$ \\ ${ }^{1}$ Renewable Energy Research Institute, Castilla-La Mancha University, Albacete, Spain \\ ${ }^{2}$ E.T.S. de Ingenieros Industriales, Castilla-La Mancha University, Albacete, Spain.
}

\begin{abstract}
This study analyzes the potential energy and water savings of the use of a closed-loop water-source heat pump system to condition an office building for the weather conditions of Madrid and Berlin. Building simulations were conducted using the EnergyPlus tool. A floor of an office building, comprising five thermal zones (four perimeter zones, oriented to the north, south, east and west, and a core zone) conditioned by a four-pipe fan-coil system was considered as the base case building. The effective thermal inertia of different walls and internal heat gains from the lighting and electric equipment, ranging between 10 and $50 \mathrm{~W} / \mathrm{m}^{2}$, were examined in the study.
\end{abstract}

\section{Introduction}

During winter operation, office buildings may require cooling in interior zones while heating is required in exterior zones. Conventional heating ventilating and air conditioning (HVAC) systems based on the use of boilers and chillers typically provide both heating and cooling demands separately (McQuiston et al., 2005), as they are unable to recover heat gains from internal zones of office buildings, due to occupants, lighting and equipment, with typical values being around 40 $W / m^{2}$.

For such cases, the use of air-conditioning systems capable of supplying perimeter heating by recovering heat gains available from internal zones, where there is a surplus and cooling is usually required over the entire year, may offer notable energy saving potential in office buildings, as internal gains due to occupants, equipment and lighting can be high.

Closed-loop water-source heat pump systems for reducing the energy consumption related to heating demands have been used in a number of applications and buildings characterized by high internal heat gains and simultaneous heating demand. This technology has been used successfully since the 1980s, re-emerging in recent years due to the growing trend in the electrification of heating in developed countries in order to facilitate greater integration of renewable production (solar, wind, etc.) into the electric grid.
One of the first experiences of recovering wasted heat for space heating applications in an industrial environment (processing of plastics) was reported by Williams (1978). This author pointed out the great potential of the heat extracted from molding machines, their hydraulics, and the plastic itself to supply part of the total space heating in manufacturing and warehouse areas, or even completely eliminate the need for such heating. Another example of the application of water-source heat pumps to satisfy comfort requirements, in this case in a large university medical center comprising teaching, hospital and research facilities, was carried out by Bahnfleth and Cramblette (1989). In this work, the authors paid special attention to the recovered energy between conditioned spaces. The benefits provided by the integration of thermal energy storage in the closed water loop were analyzed by Howell and Zaidi (1989). The simulation results of the analysis showed that the addition of approximately $180 \mathrm{~m}^{3}$ of water storage in a high capacity HVAC system could save up to $6 \%$ of the HVAC energy consumption and additional storage volumes showed a diminishing returns trend. The authors also showed that smaller temperature differences for water storage improved the energy efficiency (about $4 \%$ ) of the complete system.

However, closed-loop water-source heat pump systems are frequently implemented in shopping centers (ASHRAE, 2016) (as shops typically have high lighting heat gains whereas the shopping mall may need heating) and buildings containing data processing centers (Hinsley and Bromley, 1982) (computer server facilities, banks, etc.). Office buildings can also fit into this category, as during winter operation office buildings present significant cooling needs in the interior zones while heating is required in perimetral zones. To the best of the authors' knowledge, their application in office buildings has not been reported in the scientific literature, meaning their potential implementation and energy performance compared to conventional HVAC systems is an issue that is still not fully understood.

In the near future, the expected increase in energy costs, which will undoubtedly boost the use of heat 
recovery HVAC systems, and the widespread implementation of LED technologies in lighting systems, which on the other hand will greatly reduce lighting heat gains, will make it necessary to establish clear scenarios, trade-offs and critical values, to ascertain whether the installation of heat recovery HVAC systems is economically feasible or not. In this sense, the present study intends to contribute to a better knowledge of the application of such systems in office buildings. The increased application of these systems will likely find the higher initial costs of these types of systems compared to conventional systems (based, for the scope of this work, on four-pipe fan-coil systems served by boilers and water-cooled chillers) to be a constraint. These costs have been reported by some authors (ATECYR, 2010; ASHRAE, 2016) to be around 1.5-1.7 times higher.

This study presents and describes in detail the benefits in energy performance of the use of closed-loop water-source heat pump systems, compared to conventional air-conditioning systems based on a fourpipe fan-coil system, to condition an office building over the course of a year. In the following sections, the main characteristics and basic components of the four-pipe fan-coil systems and closed-loop heat pump systems are briefly described. Next, the most important modeling details of office buildings are highlighted. The simulation results obtained using the EnergyPlus tool for the different scenarios are then presented and discussed, and finally, the main conclusions of the work are summarized.

\section{Methods}

\section{Brief description of the four-pipe fan-coil sys- tem}

Figure 1 shows a simplified schematic diagram of a four-pipe fan-coil system served by a chiller and a boiler. This HVAC system meets the heating and cooling demands by means of two independent loops, which supply heating and cooling water as required to the four-pipe fan-coils located in the conditioned spaces. These elements contain two different coils: a heating coil and a cooling coil. Under this HVAC scheme, natural gas is consumed in the boiler, while the chiller, circulation pumps, fan-coils and cooling tower (this last element not depicted in the diagram) consume electricity. It should be taken into account that significant quantities of water are consumed by the cooling tower (make-up water) when cooling is required.

Brief description of the closed-loop watersource heat pump system

In buildings with simultaneous heating and cooling demands, the system proposed in Figure 2, typically known as a closed-loop water-source heat pump system, can help reduce air-conditioning energy consumption by taking advantage of the (free) heat avail-

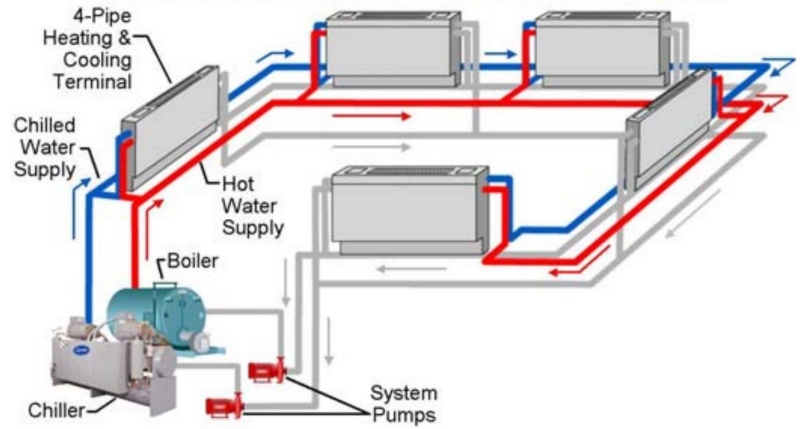

Figure 1: Simplified schematic diagram of a conventional four-pipe fan-coil system fed by a natural gas boiler and water-to-water chiller (condenser loop not included in the diagram).

able in the interior zones, which may be transferred to the perimeter zones, where heating is needed. In an ideal situation, cooling loads from the interior zones and heating loads from the exterior zones may be practically or completely balanced, requiring little or no intervention from the plants that serve the water loop.

Water typically circulates through the loop as heat transfer fluid (HTF), providing or absorbing heat from the water-to-air heat pumps connected to the water loop, which maintains a temperature between 20 and $33{ }^{\circ} \mathrm{C}$, requiring intervention from the central boilers and cooling towers only when the water temperature drops or exceeds these set-points, respectively. Integration of buffer water tanks in the loop, with the aim of increasing the thermal inertia of the loop (not considered in this study), may help to provide more prolonged operation of the equipment (avoiding excessive on-off cycling). Finally, as mentioned, a water-to-air heat pump is located in each zone to meet the heating or cooling demands of each zone, as required. It is important to note that if all the water-to-air heat pump units simultaneously demand heating or cooling (as occurs for example during the midday hours in summer), the heat pump units, together with the boiler and chiller, would have to fully meet these demands. Consequently, the energy efficiency of the described system would be similar to that of a conventional HVAC system, as little or no heat could be recovered between zones.

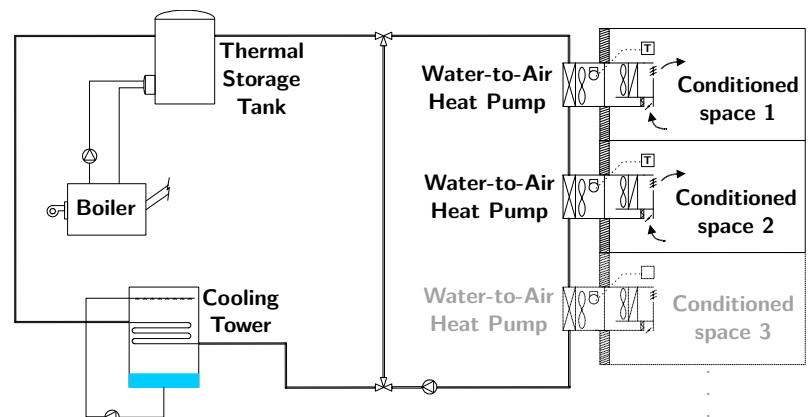

Figure 2: Simplified schematic diagram of the proposed HVAC system (water-to-air heat pumps in a closed-loop system). 


\section{Modeling of the base case building}

Building simulations have been conducted with the EnergyPlus tool (DOE, 2018), considering a floor of an office building containing the five thermal zones illustrated in Figure 3 as the building base case. This figure shows the geometry and boundary conditions of the base case building model, comprising four perimeter zones perfectly oriented to the north, south, east and west and an internal core zone, which has no contact with outdoor conditions. Different colors indicate different surfaces properties: Figure 3(a) illustrates the types of surfaces, where walls are yellow, floors and ceilings brown, and windows are blue. Figure $3(\mathrm{~b})$ depicts the boundary conditions, where blue indicates external surfaces and pink adiabatic ceiling/floors.

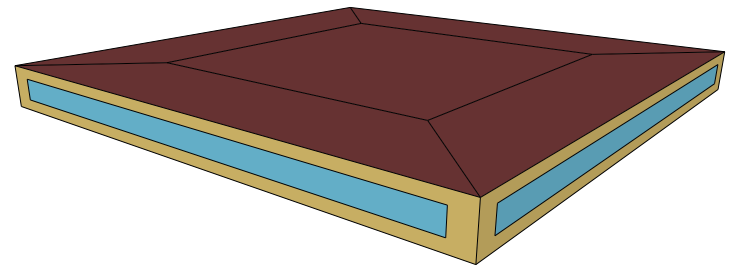

(a)

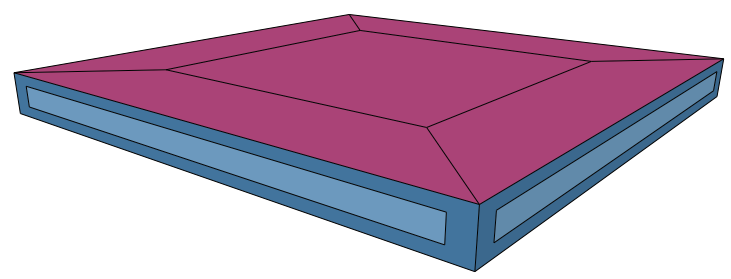

(b)

Figure 3: Different rendering views of the office base case building model.

The base case building was modeled using Euclid (Big Ladder Software, 2018), a plug-in for the geometrical environment of Sketchup (Trimble, 2018), which allows 3D geometrical models to be converted into EnergyPlus input files (*.idf files).

A summary of the buildings main geometric details, including floor, exterior wall and window-wall areas, along with the density of occupation is shown in Table 1. Because modern office buildings tend towards high window-wall ratios, especially apparent in less sunny locations such as Berlin, a high window-wall ratio (of almost 50\%) was selected for the building model. EnergyPlus default values for office workers heat gains during year round operation schedules (from 08:00-20:00h, from Mondays to Fridays) were considered in all building models (people per floor area ratio equal to 0.054 persons $/ \mathrm{m}^{2}$ ).

The influence of the thermal inertia of walls on the simulation results was taken into account by considering three different office walls for all the scenarios considered: low, medium and high thermal mass walls. Tables 2 and 3 list the assembling details of
Table 1: Building geometry and occupation details.

\begin{tabular}{|l|c|c|c|c|}
\hline & $\begin{array}{c}\text { Floor Area } \\
{\left[\mathrm{m}^{2}\right]}\end{array}$ & $\begin{array}{c}\text { Envelope Area } \\
{\left[\mathrm{m}^{2}\right]}\end{array}$ & $\begin{array}{c}\text { Window area } \\
{\left[\mathrm{m}^{2}\right]}\end{array}$ & $\begin{array}{c}\text { People } \\
{\left[\mathrm{m}^{2} / \text { person }\right]}\end{array}$ \\
\hline South Zone & 400 & 200 & 92 & 18.518 \\
\hline East Zone & 400 & 200 & 92 & 18.518 \\
\hline Core Zone & 900 & 0 & 0 & 18.518 \\
\hline North Zone & 400 & 200 & 92 & 18.518 \\
\hline West Zone & 400 & 200 & 92 & 18.518 \\
\hline Total & 2500 & 800 & 368 & \\
\hline window-wall [\%] & \multicolumn{5}{|l|}{46} \\
\hline
\end{tabular}

the layers (materials, thicknesses and relative positioning within the wall from outside to inside) of each wall, including the overall U-value and inner effective thermal mass for the case of the external walls. The details of the layers and the inner effective thermal mass are given for the case of interior floors (and ceilings), as adiabatic boundary conditions were selected for these partitions. To facilitate the reproduction of the building models by an external modeler, materials were selected from EnergyPlus dataset materials (ASHRAE, 2017). Although no significant differences were observed for the U-values of the different walls, as insulation thicknesses were kept constant for low, medium or high thermal inertia walls, it can be observed, however, that each wall provides a very different inner thermal inertia, where the inner effective thermal masses $(\mathrm{Tm})$ were computed according to Equation 1.

$$
T m=\sum_{i} \rho_{i} c_{p_{i}} t h_{i}
$$

where $\rho_{i}, c_{p_{i}}$ and $t h_{i}$ represent the density, specific heat and thickness of each layer $i$, respectively. It should be noted that this computation only takes into account layers $i$, from the innermost layers upward to reach the position of the insulation layer, in order to retain only the effect of the inner or effective thermal mass of the walls, as it was considered that the insulation layer "splits" the thermal inertia of the walls into two parts.

Table 4 summarizes the main characteristics of the building's windows, which mainly consist of large frameless double-pane windows. In addition to the construction details, the overall glass U-factor and solar heat gain coefficient (SHGC) are also provided in the table.

\section{Modeling of the HVAC systems}

EnergyPlus contains both analyzed HVAC systems as built-in "HVAC template" objects: the base case conventional system considered (a four-pipe fan-coil system served by boilers and water-cooled chillers) and the proposed system (a closed-loop water-source system with water-air heat pumps). This greatly simplifies the implementation of both HVAC systems in the EnergyPlus building models, significantly reducing modeling time. This subsection covers in some detail the most important sizing and operational aspects and parameters of the simulated water-air heat pump system. 
Table 2: Construction details of exterior walls.

\begin{tabular}{|c|c|}
\hline \multicolumn{2}{|r|}{ Exterior Walls } \\
\hline \multicolumn{2}{|r|}{ Low thermal mass } \\
\hline \multicolumn{2}{|r|}{ U-factor $=0.429 \mathrm{~W} / \mathrm{m}^{2} \mathrm{~K}$} \\
\hline \multicolumn{2}{|c|}{ Inner effective thermal mass, $T m=16.568 \mathrm{~kJ} / \mathrm{m}^{2} \mathrm{~K}$} \\
\hline \multicolumn{2}{|r|}{ Construction } \\
\hline Outer Layer & M01 100mm brick \\
\hline Layer 2 & M15 200mm heavyweight concrete \\
\hline Layer 3 & $10250 \mathrm{~mm}$ insulation board \\
\hline Layer 4 & F04 Wall air space resistance \\
\hline Inner Layer & G01a $19 \mathrm{~mm}$ gypsum board \\
\hline \multicolumn{2}{|r|}{ Medium thermal mass } \\
\hline \multicolumn{2}{|r|}{ U-factor $=0.420 \mathrm{~W} / \mathrm{m}^{2} \mathrm{~K}$} \\
\hline \multirow{2}{*}{\multicolumn{2}{|c|}{$\begin{array}{c}\text { Inner effective thermal mass, } T m=221.394 \mathrm{~kJ} / \mathrm{m}^{2} \mathrm{~K} \\
\text { Construction }\end{array}$}} \\
\hline & \\
\hline Outer Layer & M01 100mm brick \\
\hline Layer 2 & M15 200mm heavyweight concrete \\
\hline Layer 3 & $10250 \mathrm{~mm}$ insulation board \\
\hline Layer 4 & F04 Wall air space resistance \\
\hline Layer 5 & G01a $19 \mathrm{~mm}$ gypsum board \\
\hline Inner Layer & M14a $100 \mathrm{~mm}$ heavyweight concrete \\
\hline \multicolumn{2}{|r|}{ High thermal mass } \\
\hline \multicolumn{2}{|r|}{$\mathrm{U}$-factor $=0.411 \mathrm{~W} / \mathrm{m}^{2} \mathrm{~K}$} \\
\hline \multirow{2}{*}{\multicolumn{2}{|c|}{$\frac{\text { Inner effective thermal mass, } T m}{\text { Construction }}=$}} \\
\hline & Construction \\
\hline Outer Layer & M01 100mm brick \\
\hline Layer 2 & M15 200mm heavyweight concrete \\
\hline Layer 3 & $10250 \mathrm{~mm}$ insulation board \\
\hline Layer 4 & F04 Wall air space resistance \\
\hline Layer 5 & G01a $19 \mathrm{~mm}$ gypsum board \\
\hline Inner Layer & M15 200mm heavyweight concrete \\
\hline
\end{tabular}

Table 3: Construction details of interior walls.

\begin{tabular}{|c|c|}
\hline \multicolumn{2}{|r|}{ Interior Walls } \\
\hline \multicolumn{2}{|r|}{ Low thermal mass } \\
\hline \multicolumn{2}{|c|}{ Inner effective thermal mass, $\mathrm{Tm}=109.240 \mathrm{~kJ} / \mathrm{m}^{2} \mathrm{~K}$} \\
\hline \multicolumn{2}{|r|}{ Construction } \\
\hline Outer Layer & F16 Acoustic tile \\
\hline Layer 2 & F05 Ceiling air space resistance \\
\hline Inner Layer & M11 100mm lightweight concrete \\
\hline \multicolumn{2}{|r|}{ Medium thermal mass } \\
\hline \multicolumn{2}{|c|}{ Inner effective thermal mass, $\mathrm{Tm}=314.066 \mathrm{~kJ} / \mathrm{m}^{2} \mathrm{~K}$} \\
\hline \multicolumn{2}{|r|}{ Construction } \\
\hline Outer Layer & F16 Acoustic tile \\
\hline Layer 2 & F05 Ceiling air space resistance \\
\hline Layer 3 & M11 100mm lightweight concrete \\
\hline Inner Layer & M14a $100 \mathrm{~mm}$ heavyweight concrete \\
\hline \multicolumn{2}{|r|}{ High thermal mass } \\
\hline \multicolumn{2}{|c|}{ Inner effective thermal mass, $\mathrm{Tm}=518.891 \mathrm{~kJ} / \mathrm{m}^{2} \mathrm{~K}$} \\
\hline \multicolumn{2}{|r|}{ Construction } \\
\hline Outer Layer & F16 Acoustic tile \\
\hline Layer 2 & F05 Ceiling air space resistance \\
\hline Layer 3 & M11 100mm lightweight concrete \\
\hline Inner Layer & M15 200mm heavyweight concrete \\
\hline
\end{tabular}

The closed-loop water operates between 20 and 33 ${ }^{\circ} C$, serving as the heat source or sink of the waterair heat pump units with a water-side design temperature approach of $5.6^{\circ} \mathrm{C}$. The water-to-air heat pumps exhibit a nominal cooling coil COP of 3.5 and nominal heating coil COP of 4.2. The zone cooling design supply air temperature was $14{ }^{\circ} \mathrm{C}$, while a heating design supply air temperature difference of $30{ }^{\circ} \mathrm{C}$ was selected for all the simulated scenarios.

The HVAC systems and equipment were automatically sized by EnergyPlus using its intrinsic capability for that purpose (autosize), generating different sizes of HVAC systems depending on different office characteristics (internal gains, thermal mass, etc.) and weather conditions. For example, for the weather conditions of Madrid and regarding the sizing of the cooling tower, a two-speed fan with a sequential load control scheme was used with an airflow rate at high and low fan speed of 8.35 and $4.18 \mathrm{~m}^{3} / \mathrm{s}$, respectively, for the offices with an internal heat gain of $50 \mathrm{~W} / \mathrm{m}^{2}$. These values, however, corresponded to 5.82 and 2.91 $\mathrm{m}^{3} / \mathrm{s}$ for the offices with an internal heat gain of 10 $W / m^{2}$. In this regard, to facilitate the interpretation of the simulation results, Tables 5 and 6 summarize the main sizing parameters of the HVAC systems used in the study.

The chiller model used by Energyplus was the empirical model from the DOE-2 building energy simulation program (Birdsall et al., 1990). According to this model, the chiller performance at off-reference conditions is modeled using three polynomial equations: (1) Cooling Capacity, as a function of the Temperature; (2) Electric Input to Cooling Output Ratio (EIR), which is defined as the inverse of the COP, as a function of the Temperature; and (3) EIR as a function of the part load ratio. Default coefficients (EnergyPlus 9.0) for the three polynomial equations were used in this work, which are based on the following references: (1) Cooling capacity function of temperature for water cooled screw chillers, as a biquadratic curve with two independent variables based on COMNET 2010 (CONMET, 2010) Table 88; (2) EIR function of temperature for water cooled screw chillers, as a biquadratic curve with two independent variables based on COMNET 2010 Table 91; and (3) EIR function of part load ratio, as a quadratic curve based on COMNET 2010 Table 93. 
Table 5: Sizing details of the main equipment in the fan-coil systems at both locations (Madrid and Berlin).

\begin{tabular}{|c|c|c|c|c|c|}
\hline \multicolumn{6}{|c|}{ FAN-COIL SYSTEM } \\
\hline \multicolumn{6}{|c|}{ MADRID } \\
\hline \multicolumn{6}{|c|}{ BOILER NOMINAL CAPACITY $(k W)$} \\
\hline & \multicolumn{5}{|c|}{ INTERNAL GAINS $\left(\mathrm{W} / \mathrm{m}^{2}\right)$} \\
\hline & \multicolumn{5}{|c|}{ From 10 to $50\left(\mathrm{~W} / \mathrm{m}^{2}\right)$} \\
\hline High-Med.-Low Inertia & \multicolumn{5}{|c|}{76.83} \\
\hline \multicolumn{6}{|c|}{ CHILLER DESIGN CAPACITY $(k W)$} \\
\hline & \multicolumn{5}{|c|}{ INTERNAL GAINS $\left(\mathrm{W} / \mathrm{m}^{2}\right)$} \\
\hline & 10 & 20 & 30 & 40 & 50 \\
\hline High Inertia & 130.1 & 155 & 185.43 & 222.15 & 269.33 \\
\hline Medium Inertia & 131.72 & 158.99 & 158.99 & 226.11 & 276.87 \\
\hline Low Inertia & 142.69 & 181.82 & 217.21 & 276.96 & 328.89 \\
\hline \multicolumn{6}{|c|}{ COOLING TOWER FAN POWER HIGH/LOW VELOCITY $(k W)$} \\
\hline & \multicolumn{5}{|c|}{ INTERNAL GAINS $\left(\mathrm{W} / \mathrm{m}^{2}\right)$} \\
\hline & 10 & 20 & 30 & 40 & 50 \\
\hline High Inertia & $1.83 / 0.29$ & $2.17 / 0.35$ & $2.6 / 0.42$ & $3.11 / 0.5$ & $3.77 / 0.6$ \\
\hline Medium Inertia & $1.84 / 0.30$ & | $2.22 / 0.36$ & $2.22 / 0.36$ & $3.17 / 0.51$ & $3.88 / 0.62$ \\
\hline Low Inertia & $2 / 0.32$ & | $2.54 / 0.41$ & |3.04/0.49 & $3.88 / 0.62$ & $4.6 / 0.74$ \\
\hline \multicolumn{6}{|c|}{ COOLING TOWER AIRFLOW RATE AT HIGH/LOW VELOCITY $\left(\mathrm{m}^{3} / \mathrm{s}\right)$} \\
\hline & \multicolumn{5}{|c|}{ INTERNAL GAINS $\left(W / m^{2}\right)$} \\
\hline & 10 & 20 & 30 & 40 & 50 \\
\hline High Inertia & $5.17 / 2.59$ & $6.12 / 3.06$ & $7.32 / 3.66$ & $8.77 / 4.39$ & | 10.64/5.32 \\
\hline Medium Inertia & $5.2 / 2.6$ & $6.28 / 3.14$ & $6.28 / 3.14$ & $8.93 / 4.46$ & $10.93 / 5.47$ \\
\hline Low Inertia & $5.64 / 2.82$ & | 7.18/3.59 & $8.58 / 4.29$ & $10.94 / 5.47$ & $12.99 / 6.49$ \\
\hline \multicolumn{6}{|c|}{ BERLIN } \\
\hline \multicolumn{6}{|c|}{ BOILER NOMINAL CAPACITY $(k W)$} \\
\hline & \multicolumn{5}{|c|}{ INTERNAL GAINS $\left(W / m^{2}\right)$} \\
\hline & \multicolumn{5}{|c|}{ From 10 to 50} \\
\hline High-Med-Low Inertia & \multicolumn{5}{|c|}{91.8} \\
\hline \multicolumn{6}{|c|}{ CHILLER DESIGN CAPACITY $(\mathrm{kW})$} \\
\hline & \multicolumn{5}{|c|}{ INTERNAL GAINS $\left(W / m^{2}\right)$} \\
\hline & 10 & 20 & 30 & 40 & 50 \\
\hline High Inertia & 115.64 & 157.4 & 188.59 & 234.52 & 279.98 \\
\hline Medium Inertia & 117.19 & 158.42 & 158.42 & 213 & 286.11 \\
\hline Low Inertia & 136.16 & 185.64 & 237.23 & 280.05 & 344.02 \\
\hline \multicolumn{6}{|c|}{ COOLING TOWER FAN POWER HIGH/LOW VELOCITY $(k W)$} \\
\hline & \multicolumn{5}{|c|}{ INTERNAL GAINS $\left(\mathrm{W} / \mathrm{m}^{2}\right)$} \\
\hline & 10 & 20 & 30 & 40 & 50 \\
\hline High Inertia & $1.62 / 0.26$ & $2.2 / 0.35$ & $2.64 / 0.42$ & $3.28 / 0.53$ & $3.92 / 0.63$ \\
\hline Medium Inertia & $1.64 / 0.26$ & $2.22 / 0.35$ & $2.22 / 0.35$ & $2.98 / 0.48$ & $4.01 / 0.64$ \\
\hline Low Inertia & $1.91 / 0.31$ & $2.6 / 0.42$ & $3.32 / 0.53$ & $3.92 / 0.63$ & $4.82 / 0.77$ \\
\hline \multicolumn{6}{|c|}{ COOLING TOWER AIRFLOW RATE AT HIGH/LOW VELOCITY $\left(\mathrm{m}^{3} / \mathrm{s}\right)$} \\
\hline & \multicolumn{5}{|c|}{ INTERNAL GAINS $\left(\mathrm{W} / \mathrm{m}^{2}\right)$} \\
\hline & 10 & 20 & 30 & 40 & 50 \\
\hline High Inertia & $4.29 / 2.14$ & $5.83 / 2.92$ & $6.99 / 3.49$ & $8.69 / 4.35$ & | 10.38/5.19 \\
\hline Medium Inertia & $4.34 / 2.17$ & $5.87 / 2.94$ & $5.87 / 2.94$ & $7.89 / 3.95$ & $10.6 / 5.3$ \\
\hline Low Inertia & $5.05 / 2.52$ & | 6.88/3.44 & $8.79 / 4.4$ & $10.38 / 5.2$ & | $12.75 / 6.37$ \\
\hline
\end{tabular}

\section{Weather conditions considered in simulations}

The performance of office buildings is not as sensitive to weather conditions as that of residential buildings because of their inherent high internal heat gains due to people, lighting and electric equipment. However, the differential performance of HVAC systems can vary significantly from one location to another, especially due to the high window-wall ratio considered in the building model, which makes the buildings thermal response highly sensitive to outdoor temperatures and solar radiation levels. To assess the differential performance of HVAC systems for different weather conditions, annual simulations were conducted considering the different typical meteorologi-
Table 6: Sizing details of the main equipment in the water-to-air heat pump systems at both locations (Madrid and Berlin).

\begin{tabular}{|c|c|c|c|c|c|}
\hline \multicolumn{6}{|c|}{ WATER-TO-AIR HEAT PUMP SYSTEM } \\
\hline \multicolumn{6}{|c|}{ MADRID } \\
\hline \multicolumn{6}{|c|}{ BOILER NOMINAL CAPACITY $(k W)$} \\
\hline & \multicolumn{5}{|c|}{ INTERNAL GAINS $\left(\mathrm{W} / \mathrm{m}^{2}\right)$} \\
\hline & 10 & 20 & 30 & 40 & 50 \\
\hline High Inertia & 141.55 & 170.62 & 212.05 & 246.65 & 277.65 \\
\hline Medium Inertia & 142.78 & 175.68 & 209.98 & 252.02 & 310.83 \\
\hline Low Inertia & 157.5 & 201.42 & 242.03 & 310.04 & 369.41 \\
\hline \multicolumn{6}{|c|}{ COOLING TOWER FAN POWER HIGH/LOW VELOCITY $(k W)$} \\
\hline & \multicolumn{5}{|c|}{ INTERNAL GAINS $\left(\mathrm{W} / \mathrm{m}^{2}\right)$} \\
\hline & 10 & 20 & 30 & 40 & 50 \\
\hline High Inertia & $1.51 / 0.24$ & $\mid 1.82 / 0.29$ & $2.26 / 0.36$ & $2.63 / 0.42$ & $2.96 / 0.47$ \\
\hline Medium Inertia & $1.52 / 0.24$ & $1.87 / 0.3$ & $2.24 / 0.36$ & $2.69 / 0.43$ & $3.31 / 0.53$ \\
\hline Low Inertia & $1.68 / 0.27$ & $\mid 2.15 / 0.34$ & $2.58 / 0.41$ & $3.31 / 0.53$ & $3.94 / 0.63$ \\
\hline \multicolumn{6}{|c|}{ COOLING TOWER AIRFLOW RATE AT HIGH/LOW VELOCITY $\left(\mathrm{m}^{3} / \mathrm{s}\right)$} \\
\hline & \multicolumn{5}{|c|}{ INTERNAL GAINS $\left(\mathrm{W} / \mathrm{m}^{2}\right)$} \\
\hline & 10 & 20 & 30 & 40 & 50 \\
\hline High Inertia & $4.26 / 2.13$ & $\mid 5.13 / 2.57$ & $6.38 / 3.19$ & $7.42 / 3.71$ & $8.35 / 4.18$ \\
\hline Medium Inertia & $4.3 / 2.15$ & $\mid 5.29 / 2.64$ & $6.32 / 3.16$ & $7.58 / 3.79$ & $9.35 / 4.68$ \\
\hline Low Inertia & $4.74 / 2.37$ & $6.06 / 3.03$ & $7.28 / 3.64$ & $9.34 / 4.67$ & $11.11 / 5.56$ \\
\hline \multicolumn{6}{|c|}{ BERLIN } \\
\hline \multicolumn{6}{|c|}{ BOILER NOMINAL CAPACITY $(k W)$} \\
\hline & \multicolumn{5}{|c|}{ INTERNAL GAINS $\left(\mathrm{W} / \mathrm{m}^{2}\right)$} \\
\hline & 10 & 20 & 30 & 40 & 50 \\
\hline High Inertia & 124.32 & 169.82 & 204.07 & 253.88 & 303.25 \\
\hline Medium Inertia & 126.49 & 171.36 & 209.3 & 231.87 & 311.47 \\
\hline Low Inertia & 146.94 & 201.14 & 257.49 & 304.93 & 374.87 \\
\hline \multicolumn{6}{|c|}{ COOLING TOWER FAN POWER HIGH/LOW VELOCITY $(k W)$} \\
\hline & \multicolumn{5}{|c|}{ INTERNAL GAINS $\left(\mathrm{W} / \mathrm{m}^{2}\right)$} \\
\hline & 10 & 20 & 30 & 40 & 50 \\
\hline High Inertia & $1.33 / 0.21$ & $1.81 / 0.29$ & $2.18 / 0.35$ & $2.71 / 0.43$ & $3.23 / 0.52$ \\
\hline Medium Inertia & $1.35 / 0.22$ & $\mid 1.83 / 0.29$ & $2.23 / 0.36$ & $2.47 / 0.4$ & $3.32 / 0.53$ \\
\hline Low Inertia & $1.57 / 0.25$ & $\mid 2.14 / 0.34$ & $2.75 / 0.44$ & $3.25 / 0.52$ & $4.0 / 0.64$ \\
\hline \multicolumn{6}{|c|}{ COOLING TOWER AIRFLOW RATE AT HIGH/LOW VELOCITY $\left(\mathrm{m}^{3} / \mathrm{s}\right)$} \\
\hline & \multicolumn{5}{|c|}{ INTERNAL GAINS $\left(\mathrm{W} / \mathrm{m}^{2}\right)$} \\
\hline & 10 & 20 & 30 & 40 & 50 \\
\hline High Inertia & $3.51 / 1.75$ & $4.79 / 2.4$ & $5.76 / 2.88$ & $7.17 / 3.58$ & $8.56 / 4.28$ \\
\hline Medium Inertia & $3.57 / 1.79$ & $4.84 / 0.48$ & $5.91 / 2.95$ & $6.55 / 3.27$ & $8.79 / 4.4$ \\
\hline Low Inertia & $4.15 / 2.07$ & $5.68 / 2.84$ & $7.27 / 3.63$ & $8.61 / 4.3$ & $10.58 / 5.29$ \\
\hline
\end{tabular}

cal weather conditions of Madrid and Berlin.

Figure 4 plots year-round comparisons of the outdoor dry bulb temperatures of the typical meteorological weather files used for Madrid and Berlin. Figure 4 (a) shows year-round hourly values, while Figure 4 (b) depicts the histograms and cumulative frequency of occurrence of both locations. As expected, the blue lines, which correspond to weather conditions in Berlin, indicate much colder temperatures, for example, while for Madrid around 65\% of the hours per year, the outdoor temperatures are below $18^{\circ} \mathrm{C}$. For Berlin, this value increases to approximately $85 \%$, denoting much colder year-round temperatures, as clearly shown by the significant displacement to the left of the cumulative frequency of occurrence curve.

A similar pattern is observed with regard to the horizontal solar radiation from the typical meteorological 


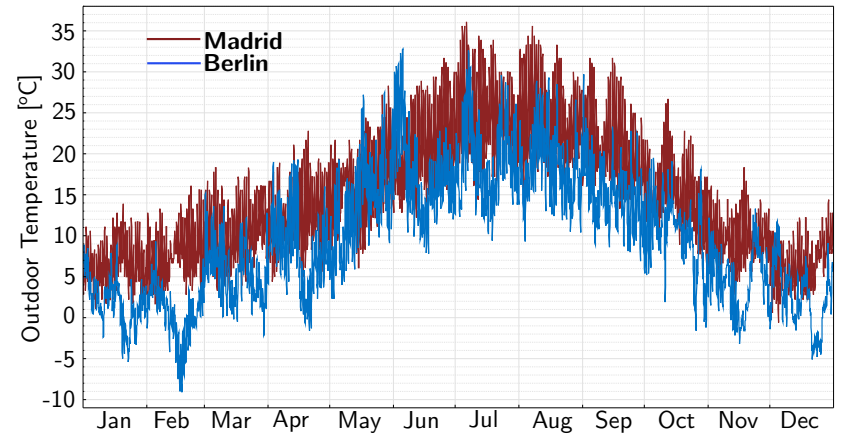

(a)

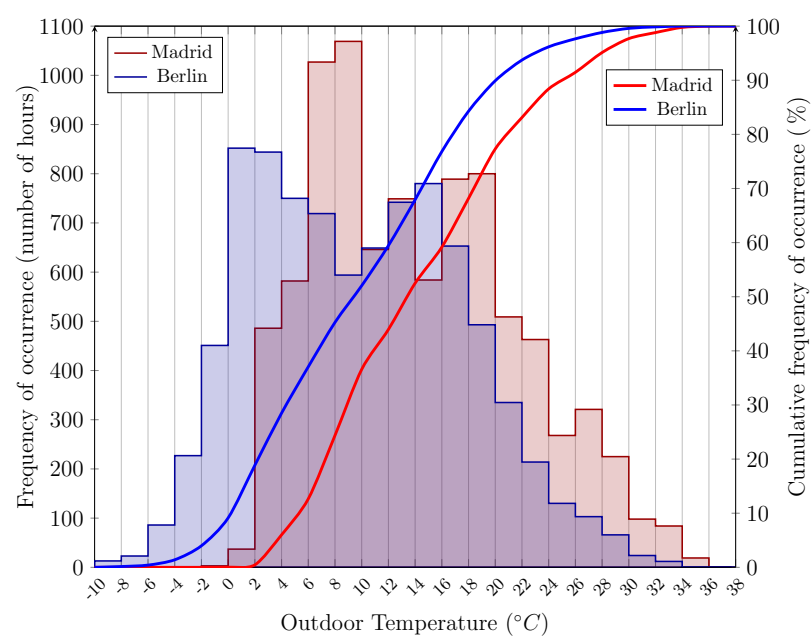

(b)

Figure 4: Comparison of outdoor dry bulb temperatures in Madrid and Berlin.

weather data of both locations, as shown in Figure 5, which represents a back-to-back comparison of the solar radiation heat maps distinguishing the hours of the day and the months along the year. Figure 5 (a) corresponds to Madrid and Figure 5 (b) to Berlin. As expected, longer sunny periods throughout the year associated with higher radiations levels are clearly observed for Madrid, reporting peak solar radiation levels around $1000 \mathrm{~W} / \mathrm{m}^{2}$ during central hours (from 12:00 to 16:00) in summer. Much shorter sunny periods with lower intensities are shown for the case of Berlin, with peak solar radiation levels no higher than $900 \mathrm{~W} / \mathrm{m}^{2}$ during summer midday hours.

\section{Results}

A total of 108 Energyplus simulations $(2 \times 3 \times 9 \times 2)$ were conducted in order to consider all the potential scenarios from the combination of the weather conditions of Madrid and Berlin (2); the low, medium and high thermal mass walls (3); the different internal office heat gains due to lighting and equipment (with values ranging from 10 up to $50 \mathrm{~W} / \mathrm{m}^{2}$, with increments of $\left.5 \mathrm{~W} / \mathrm{m}^{2}\right)(9)$; and the two HVAC systems mentioned above (2).

From all the possible EnergyPlus output variables, three year-round key performance indicators (KPI) per unit of conditioned area were selected to evaluate

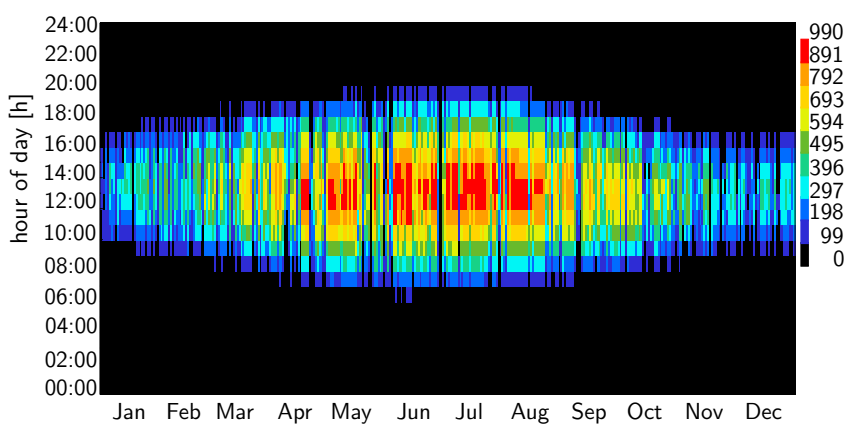

(a)

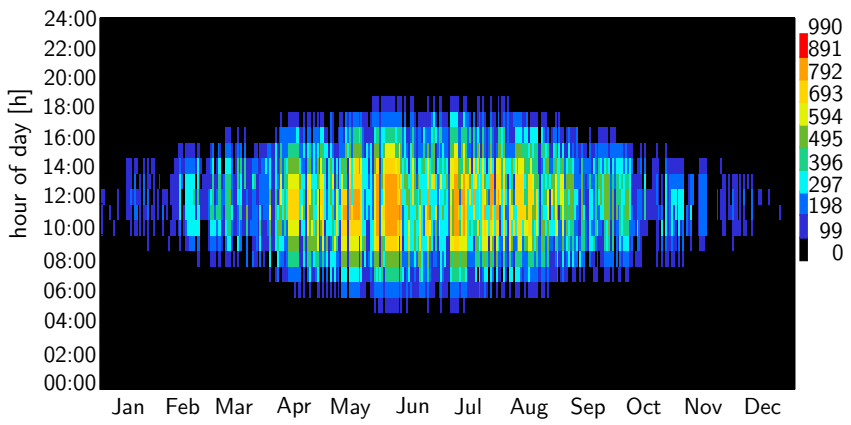

(b)

Figure 5: Distribution maps of the yearly global horizontal radiation in Madrid and Berlin.

the differential performance of the closed-loop watersource heat pump system compared to the fan-coil system. These were the HVAC system electricity savings $\left(k W h / m^{2}\right.$ year $)$, the HVAC system natural gas savings $\left(k W h / m^{2}\right.$ year $)$ and the cooling tower water savings (liters $/ \mathrm{m}^{2}$ year). To better understand the simulation results, it is important to note that the base case fan-coil systems are served by a natural gas boiler and an electric chiller, as heating and cooling generation plants. Pumps and fans, which consume electrical energy, are used to transport water and air. On the other hand, the closed-loop heat pump system contains a natural gas boiler and a cooling tower (not a chiller) which consume electrical energy in their fans and pumps, with both plants being fed by the same water loop, containing a pump to circulate a water flow rate through the loop that consumes electrical energy. Reversible heat pumps are situated at zone level (one per conditioned zone), which consume electrical energy (through their corresponding compressors and fans).

The KPI results obtained from the Energyplus simulations are shown in Figure 6, where the red lines correspond to results obtained using the weather conditions of Madrid, and the blue lines to Berlin (in accordance with previous figures). In addition, green or red shaded areas have been included in the figures to clearly highlight the scenarios where savings occur (green) or do not occur (red), that is, scenarios where the proposed water closed-loop heat pump system does not consume less electricity or water over a year than the base case fan-coil system, consuming, conversely, more energy or water resources. 

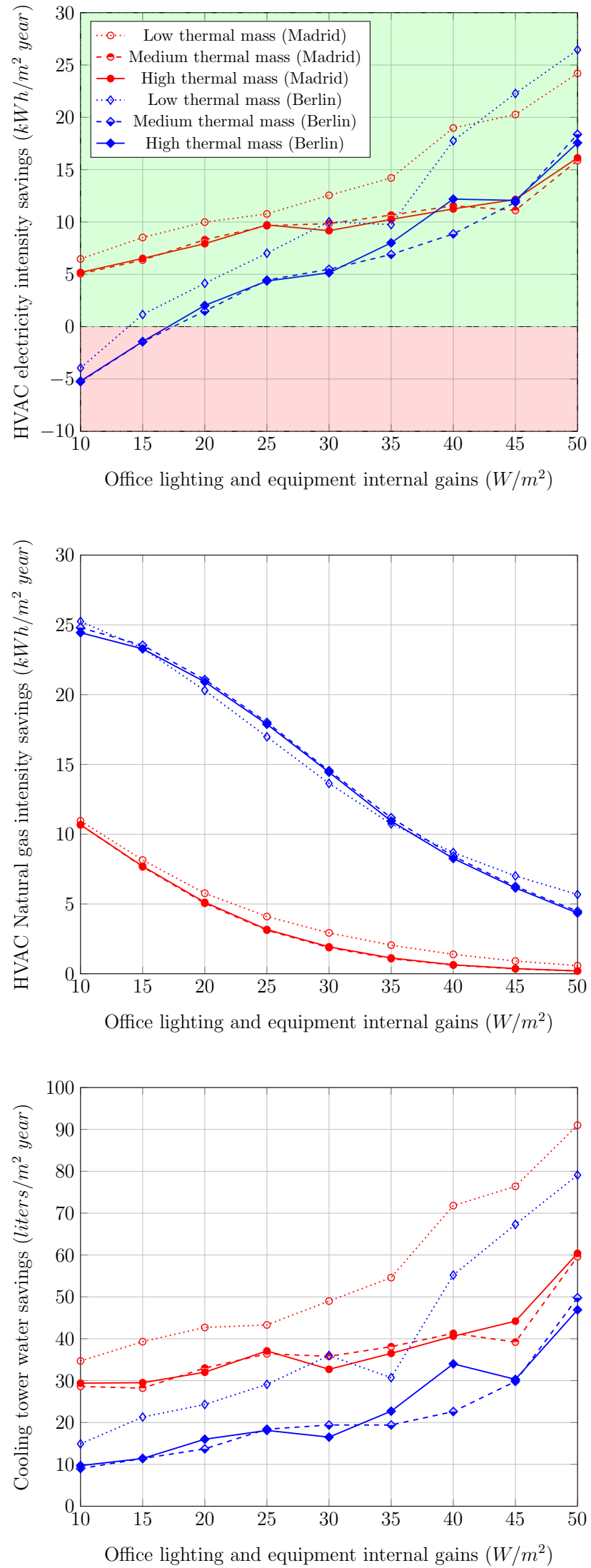

Figure 6: Plot of the KPI results obtained from the EnergyPlus simulations for the studied scenarios.

\section{Discussion}

The following points may be highlighted from the analysis of the simulation results plotted in Figure 6:

1. A general trend is observed for both weather conditions, indicating that higher HVAC electricity and cooling water savings are reached for higher office lighting and equipment heat gains, as cooling needs increase in proportion to these internal heat gains. Conversely, a diminishing trend in natural gas savings is observed for higher internal gains, as a consequence of the lower heating needs. This suggests that the closed-loop heat pump system is able to manage greater amounts of internal heat gains (heat recovery) to meet office heating demands, requiring less conventional energy to maintain comfortable indoor conditions, increasing, in turn, its energy efficiency. For the weather conditions of Madrid, the simulation results indicate approximate potential year-round KPIs of between 5 and $25 \mathrm{kWh} / \mathrm{m}^{2}$ year with regard to electricity savings, between 0.5 and 11 $k W h / m^{2}$ year for natural gas savings, and between 30 and 90 liters $/ \mathrm{m}^{2}$ year with respect to cooling water savings (cooling tower make-up water). For the weather conditions of Berlin, these same KPI savings correspond to ranges between -5 and $25 \mathrm{kWh} / \mathrm{m}^{2}$ year for electricity, between 5 and $25 \mathrm{kWh} / \mathrm{m}^{2}$ year for natural gas, and between 10 and 80 liters $/ \mathrm{m}^{2}$ year for cooling water.

2. The effect of the walls thermal mass can be considered negligible with regard to natural gas consumption (associated with the heating demand), but can be significant for electricity and water savings (related to cooling loads). Especially significant may be the influence of thermal inertia for scenarios with higher internal gains. The simulation results suggest that relatively light building envelopes (associated with rapid thermal responses) show a sufficiently good performance. However, the use of walls with a high thermal mass is not recommended, as effects associated with energy buffer and time delays introduced by the inertia may produce detrimental effects on energy and water consumption for a typical office with a daily working schedule from 08:00-20:00h.

3. Because the closed-loop water-source heat pump system meets part of the heating load by means of the boiler and the remaining part through the water-air heat pump, notable savings in natural gas are found, especially for Berlin. Low internal gains levels, albeit with slight increases in electricity consumption, are reported for these scenarios. For values of internal heat gains greater than $15-20 \mathrm{~W} / \mathrm{m}^{2}$ (depending on the walls thermal inertia), noticeable savings are observed for Berlin for both electricity and natural gas. No trade-off values were observed for the case of Madrid, as 
the closed-loop water-source heat pump system behaves more efficiently for all scenarios with regard to electricity, natural gas and cooling water consumption.

\section{Conclusions}

The results from the EnergyPlus simulations conducted under the scope of this work have revealed that the use of air-conditioning systems capable of supplying perimeter heating by recovering internal heat gains due to occupants, electric equipment and lighting from internal zones, may provide potential for significant energy savings in office buildings. The highest savings ratios were found to be values of between 5 and $25 \mathrm{kWh} / \mathrm{m}^{2}$ year with regard to electricity for the weather conditions of Madrid, between 5 and $25 \mathrm{kWh} / \mathrm{m}^{2}$ year for natural gas for the weather conditions of Berlin, and between 30 and 90 liters $/ \mathrm{m}^{2}$ year with respect to the water consumed by the cooling tower in Madrid. For the majority of the simulated scenarios, higher energy and water savings were obtained in office buildings with higher associated internal heat gain levels, suggesting that the closed-loop heat pump system is able to manage greater amounts of internal heat gains (heat recovery) to meet office heating demands, consequently consuming less conventional energy.

Office building walls with high thermal inertia may produce detrimental effects on the performance of closed-loop water-source heat pump systems because of the unpredicted load displacement effect from heating to cooling office needs, which may produce overall negative results in certain scenarios.

Although this work reports significant energy and water savings, the initial costs of closed-loop watersource heat pump system systems compared to conventional systems (taking HVAC solutions based on four-pipe fan-coil systems served by boilers and water-cooler chillers as our reference) were estimated to be around 1.5-1.7 times higher. Thus, it is necessary to perform complete life-cycle cost analyses to ascertain the economic feasibility of heat recovery systems in particular office buildings.

\section{Acknowledgments}

This work was partially funded by the Spanish Government (Project ENE2016-78908-R) and the regional Government of Castilla-La Mancha (Project SBPLY/17/180501/000412).

\section{Nomenclature}

- ASHRAE: American Society of Heating, Refrigerating, and Air Conditioning Engineers

- COP: Coefficient Of Performance

- EIR: Electric Input to cooling output Ratio

- HVAC: Heating Ventilating and Air Conditioning
- HTF: Heat Transfer Fluid

- KPI: Key Performance Indicator

- LED: Light-Emitting Diode

- SHGC : Solar Heat Gain Coefficient

\section{References}

ASHRAE (2016). HVAC Systems and Equipment. American Society of Heating, Refrigerating, and Air Conditioning Engineers, Atlanta, GA.

ASHRAE (2017). Handbook Of Fundamentals (HOF). American Society of Heating, Refrigerating, and Air Conditioning Engineers, Atlanta, GA.

ATECYR (edited by) (2010). Manual de fundamentos de climatización. ATECYR.

Bahnfleth, D. R. and D. Cramblette (1989). Energy recovery in a medical center. HPAC Heating, Piping, Air Conditioning 61(3), 71-79.

Big Ladder Software, L. (last accessed on Feb 2018). Euclid, a geometry editor for sketchup.

Birdsall, B., W. F. Buhl, K. L. Ellington, A. E. Erdem, and F. C. Winkelmann (1990). Overview of the doe-2 building energy analysis program.

CONMET (2010). Conmet. standardizing energy modeling for buildings.

DOE (last accessed on Jan 2018). Energyplus. energy simulation software. u.s. department of energy (doe) building technologies office (bto).

Hinsley, R. and A. Bromley (1982). Energy conservation in computer rooms. pp. 4. 233-4. 242.

Howell, R. and J. Zaidi (1989). Effects of storage parameters on the energy requirements for closed water loop heat pump systems. Volume 118, pp. $9-15$.

McQuiston, F. C., J. D. Parker, and J. D. Spitler (2005). Heating, ventilating, and air conditioning: analysis and design. John Wiley and Sons., Inc., New York, NY.

Trimble (last accessed on Feb 2018). Sketchup. trimble navigation limited.

Williams, D. C. (1978). Reusing waste energy for space heating in plastics plants. pp. 202-206. 